Provided for non-commercial research and education use. Not for reproduction, distribution or commercial use.

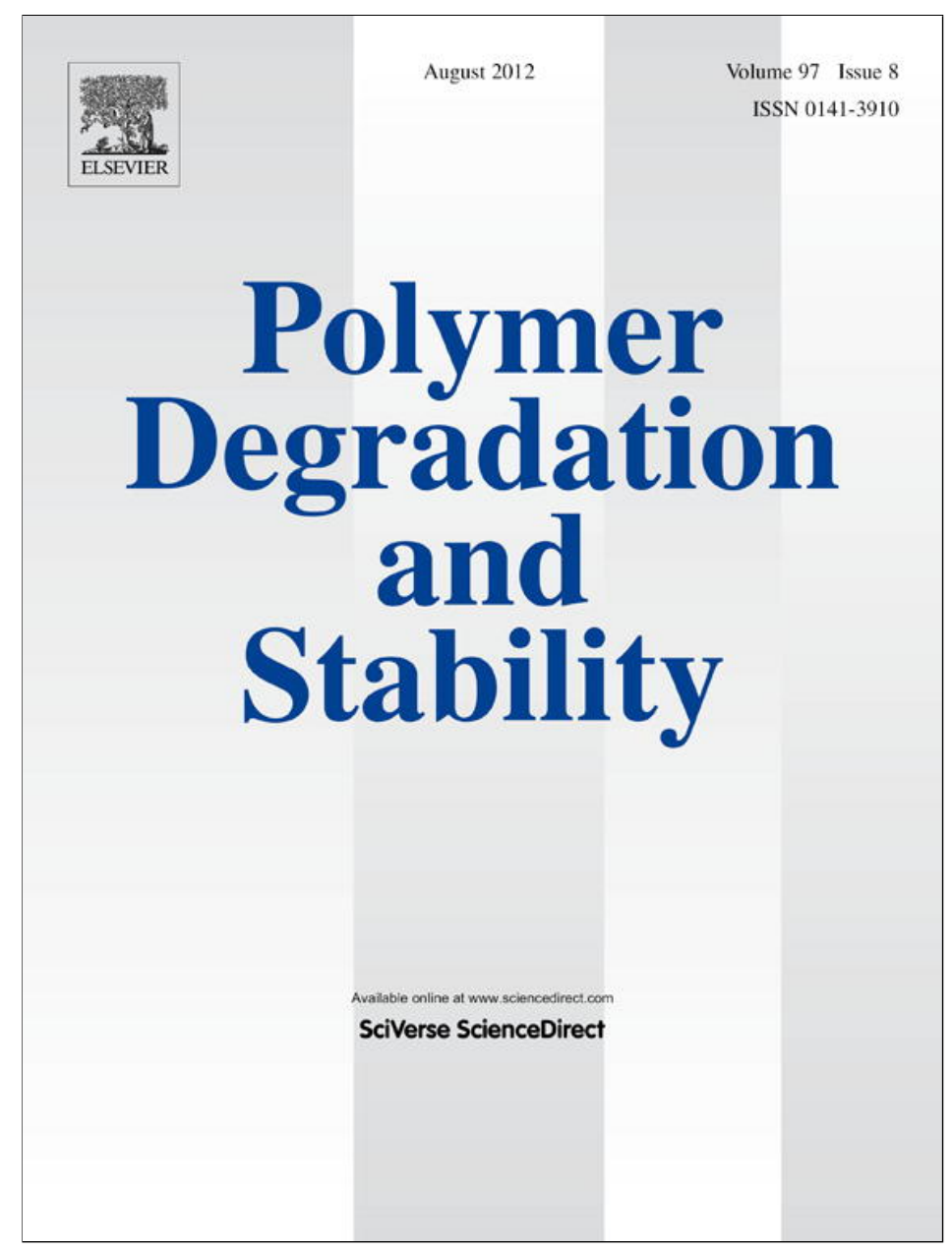

This article appeared in a journal published by Elsevier. The attached copy is furnished to the author for internal non-commercial research and education use, including for instruction at the authors institution and sharing with colleagues.

Other uses, including reproduction and distribution, or selling or licensing copies, or posting to personal, institutional or third party websites are prohibited.

In most cases authors are permitted to post their version of the article (e.g. in Word or Tex form) to their personal website or institutional repository. Authors requiring further information regarding Elsevier's archiving and manuscript policies are encouraged to visit:

http://www.elsevier.com/copyright 


\title{
PMMA-titania nanocomposites: Properties and thermal degradation behaviour
}

\author{
Tshwafo Elias Motaung ${ }^{a}$, Adriaan Stephanus Luyt ${ }^{\mathrm{a}, *}$, Federica Bondioli ${ }^{\mathrm{b}}$, Massimo Messori ${ }^{\mathrm{b}}$, \\ Maria Luisa Saladino ${ }^{\mathrm{c}}$, Alberto Spinella ${ }^{\mathrm{d}}$, Giorgio Nasillo ${ }^{\mathrm{c}, \mathrm{d}}$, Eugenio Caponetti ${ }^{\mathrm{c}, \mathrm{d}}$ \\ a Department of Chemistry, University of the Free State (Qwaqwa Campus), Private Bag X13, Phuthaditjhaba 9866, South Africa \\ ${ }^{\mathrm{b}}$ Dipartimento di Ingegneria dei Materiali e dell'Ambiente, Università di Modena e Reggio Emilia, Via Vignolese 905/A, Modena I-41125, Italy \\ ${ }^{c}$ Department of Chemistry “S. Cannizzaro", University of Palermo, Parco d'Orleans II-Viale delle Scienze pad. 17, Palermo I-90128, Italy \\ d Centro Grandi Apparecchiature-UniNetLab, University of Palermo, Via F. Marini 14, Palermo I-90128, Italy
}

\section{A R T I C L E I N F O}

\section{Article history:}

Received 7 December 2011

Received in revised form

11 May 2012

Accepted 21 May 2012

Available online 28 May 2012

\section{Keywords:}

PMMA

Titania

Nanocomposites

Interfacial interaction

Properties

Degradation kinetics

\begin{abstract}
A B S T R A C T
Titania nanoparticles were prepared using a sol-gel method and calcination at 200 and $600{ }^{\circ} \mathrm{C}$ in order to obtain anatase and rutile phases, respectively. The obtained powders were used to prepare PMMAtitania nanocomposites by a melt compounding method. The effect of the crystalline phase and the amount of titania, in the range $1-5 \mathrm{wt} . \%$, on the morphology, mechanical properties and thermal degradation kinetics of PMMA was investigated by means of X-ray diffractometry (XRD), transmission electron microscopy (TEM), ${ }^{13} \mathrm{C}$ cross-polarization magic-angle spinning nuclear magnetic resonance spectroscopy $\left({ }^{13} \mathrm{C}\left\{{ }^{1} \mathrm{H}\right\} \mathrm{CP}-\mathrm{MAS}\right.$ NMR), including the measurement of proton spin-lattice relaxation time in the rotating frame $\left(T_{1 \rho}(\mathrm{H})\right)$, in the laboratory frame $\left(T_{1}(\mathrm{H})\right)$ and cross polarization times $\left(T_{\mathrm{CH}}\right)$, and dynamic mechanical analysis (DMA), thermogravimetric analysis (TGA), and Fourier-transform infrared (FTIR) spectroscopy. Results showed that both types of titania were well dispersed in the polymeric matrix, whose structure remained amorphous. The two types of nanoparticles influenced the degradation of the polymer in different ways because of their different carbon content, particle size and crystal structures.
\end{abstract}

(c) 2012 Elsevier Ltd. All rights reserved.

\section{Introduction}

Incorporation of inorganic nanoparticles into a polymer matrix has led to composites with improved thermal and mechanical properties [1-3]. There are a number of recent papers reporting on thermal degradation studies on poly(methyl methacrylate) (PMMA) containing boehmite, alumina, iron oxide and different clays [4-9]. It was found that metal oxides have a pronounced effect on the morphology, as well as mechanical and thermal behaviour of PMMA. Some authors found that the well dispersed metal oxide nanoparticles in PMMA improved its mechanical properties, and increased its thermal stability and activation energy of thermal degradation [5-8]. These observations were attributed to strong interfacial interaction and stabilization of the free radicals by the inorganic compounds. However, Laachachi et al., in their investigation of PMMA nanocomposites with organically modified clays, found a decrease in the thermal stability of PMMA and attributed it to a catalytic effect of the clays on PMMA degradation [9].

\footnotetext{
* Corresponding author. Tel.: +27 587185314; fax: +27 587185444.

E-mail address: luytas@qwa.ufs.ac.za (A.S. Luyt).
}

The introduction of titania $\left(\mathrm{TiO}_{2}\right)$ into a PMMA matrix received much attention due to improvements in the glass transition and thermal stability of the composites. Several methods have been used to prepare poly(methyl methacrylate)-titania ( $\mathrm{PMMA}-\mathrm{TiO}_{2}$ ) nanocomposites, including ex-situ sol-gel polymerization, radical polymerization and solution mixing $[2,3,10]$. For nanocomposites prepared via in situ bulk polymerization it was found that the presence of $\mathrm{TiO}_{2}$ retarded the thermal decomposition of the polymer [11]. This was attributed to the excellent interaction of the polymer chains with the $\mathrm{TiO}_{2}$ nanoparticles and the barrier effect to the evaporation of small molecules generated during the thermal decomposition of the PMMA matrix. The opposite trend, where the presence of $\mathrm{TiO}_{2}$ in a PMMA matrix did not enhance the thermal stability, was also observed and it was associated with the evaporation of physisorbed water [12]. Storage and loss modulus, glass transition temperature $\left(T_{\mathrm{g}}\right)$, pendulum hardness and activation energy of the thermal degradation of the nanocomposites increased with increasing $\mathrm{TiO}_{2}$ content in PMMA- $\mathrm{TiO}_{2}$ nanocomposites [13]. It was also found that the presence of $\mathrm{TiO}_{2}$ in the PMMA matrix could lead to a decrease in $T_{\mathrm{g}}$ [2]. The decrease in this case was associated with significant formation of agglomerates and poor interaction. In another study the decrease in $T_{\mathrm{g}}$ was attributed to the increased length of the 
polymer chains grown from the nanoparticles due to increased polymerization time [14].

$\mathrm{PMMA} \mathrm{TiO}_{2}$ nanocomposites prepared via solution mixing were also investigated $[15,16]$. The nanocomposites showed significant improvement in mechanical performance, thermal stability, glass transition temperature and activation energy of thermal degradation of the PMMA. Similar results were found for $\mathrm{PMMA}^{-\mathrm{TiO}_{2}}$ nanocomposites prepared through extrusion and rheometer mixing [17-19]. In these cases the titania was synthesized and modified by pure catechol. The improvement in the properties was attributed to good interfacial interaction and nanoparticles dispersion, which led to immobilization of the polymer chains. In contrast, the unmodified nanoparticles showed a decrease in glass transition which was linked to repulsive interaction with the surrounding polymer chains [15].

A review paper on the photoinduced reactivity of titanium dioxide [20] discusses the differences between anatase and rutile titania, all of which may cause the nanoparticles of these two titania phases to interact differently when incorporated into a polymer matrix. First of all the exposed planes of these nanoparticles are different because, although both anatase and rutile titania have octahedral structures, anatase titania can be regarded to be built up from octahedrals that are connected by their vertices, while in rutile titania the edges are connected. Further it was found that the anatase phase has a different oxygen vacancy than the rutile phase, as well as higher electron mobility, lower dielectric constant, lower density, lower deposition temperature and lower surface energy. Both these titania phases were found to have catalytic properties.

Most of the reported studies concentrated on commercial anatase titania incorporated in PMMA, while little information was provided regarding incorporation of the rutile phase into PMMA. No systematic comparison of the properties of $\mathrm{PMMA}^{-\mathrm{TiO}_{2}}$ nanocomposites, containing respectively anatase and rutile titania, has been reported in literature. The purpose of this study was to prepare PMMA-TiO nanocomposites, containing anatase and rutile titania respectively, through melt compounding, and analysing the sample morphologies as well as their degradation and thermomechanical behaviour. The fillers were prepared by using sol-gel combustion methods. The nanoparticles and the composites were characterized using oriented finite element analysis (OFE), X-ray diffractometry (XRD), transmission electron microscopy (TEM), ${ }^{13} \mathrm{C}$ cross-polarization magic-angle spinning nuclear magnetic resonance spectrometry $\left({ }^{13} \mathrm{C}\left\{{ }^{1} \mathrm{H}\right\}\right.$ CP-MAS NMR), including the measurement of proton spin-lattice relaxation time in the rotating frame $\left(T_{1 \rho}(\mathrm{H})\right)$, in the laboratory frame $\left(T_{1}(\mathrm{H})\right)$ and cross polarization times $\left(T_{\mathrm{CH}}\right)$, dynamic mechanical analysis (DMA), thermogravimetric analyses (TGA), and TGA-Fourier-transform infrared spectroscopy (TGA-FTIR).

\section{Experimental}

\subsection{Materials}

Titanium isopropoxide $\left(\mathrm{Ti}(\mathrm{i}-\mathrm{OPr})_{4}\right.$, Sigma Aldrich), nitric acid (Sigma Aldrich), and glycine (Sigma Aldrich) were used as received. Conductivity grade water (resistance $=18.1 \mathrm{M} \Omega$ ) was used. Commercial grade poly(methyl methacrylate) (PMMA, Altuglas ${ }^{\circledR}$ V920T) produced by Bayer Materials Science, Italy, having a melt flow rate at $230{ }^{\circ} \mathrm{C} / 3.8 \mathrm{~kg}$ of $1 \mathrm{~g} / 10 \mathrm{~min}$, and an $M_{\mathrm{w}}=350000$, was used in pellet form. The polymer was dried at $120{ }^{\circ} \mathrm{C}$ overnight under static vacuum before processing.

\subsection{Titania preparation}

Titania was prepared by the sol-gel combustion of aqueous solutions containing $\mathrm{TiO}\left(\mathrm{NO}_{3}\right)_{2}$, as precursor, and glycine as fuel.
Titanium isopropoxide, $\mathrm{Ti}(\mathrm{i}-\mathrm{OPr})_{4}$, was hydrolysed for $1 \mathrm{~h}$ under magnetic stirring to obtain titanyl hydroxide, $\mathrm{TiO}(\mathrm{OH})_{2}$. The obtained titanyl hydroxide was reacted with nitric acid $(1 \mathrm{~h})$ to produce an aqueous solution of titanyl nitrate $\left[\mathrm{TiO}\left(\mathrm{NO}_{3}\right)_{2}\right]$ that was used as the precursor for the synthesis of titania. The molar ratio $\mathrm{Ti}(\mathrm{i}-\mathrm{OPr})_{4}: \mathrm{H}_{2} \mathrm{O}$ and of $\mathrm{TiO}(\mathrm{OH})_{2}: \mathrm{HNO}_{3}$ was fixed at $1: 4$. The aqueous solution of titanyl nitrate was mixed with glycine (glycine:titanyl nitrate molar ratio $=2$ ) and ammonium nitrate (glycine: $\mathrm{NH}_{4} \mathrm{NO}_{3}$ molar ratio $=0.5$ ) followed by heating in an oven at $80{ }^{\circ} \mathrm{C}$ until complete dehydration. The obtained gel was ignited in an electric furnace at $450^{\circ} \mathrm{C}$. Once ignited, the combustion process was completed in a very short time ( $5 \mathrm{~min}$ ) with the appearance of flame. After the synthesis, the slightly agglomerated titania powder was divided in two parts that were thermally treated in air for $2 \mathrm{~h}$ at $200{ }^{\circ} \mathrm{C}$ and at $600{ }^{\circ} \mathrm{C}$ in order to crystallize the anatase and rutile phases, respectively. After the treatment, the colours of the powders were black and white, respectively.

\subsection{Preparation of the nanocomposites}

The PMMA pellets were thoroughly mixed with 1, 2 and 5 wt.\% titania for $10 \mathrm{~min}$ at $200^{\circ} \mathrm{C}$ and $30 \mathrm{rpm}$ in a $50 \mathrm{~mL}$ internal mixer of a Brabender Plastograph (Duisburg, Germany). The mixed samples were melt-pressed into $1 \mathrm{~mm}$ thick sheets at $200{ }^{\circ} \mathrm{C}$ for $5 \mathrm{~min}$.

\subsection{Analysis methods}

Oriented finite element analysis (OFE) was carried out on a Carlo Erba EA 1110 apparatus in order to determine the residual carbon content in the titania particles.

Transmission electron microscopy (TEM) micrographs were acquired by using a JEM-2100 (JEOL, Japan) electron microscope, equipped with an X-ray energy dispersive spectrometer (EDS, Oxford, model INCA ENERGY-200T) for analysis of elements, operating at a $200 \mathrm{kV}$ accelerating voltage. A few tens of a milligram of the powders were dispersed in $2 \mathrm{~mL}$ of isopropanol and a small drop of the dispersion was deposited on a 300 mesh carbon-coated copper grid, which was introduced into the TEM analysis chamber after complete solvent evaporation. Thin nanocomposite samples of about $50 \mathrm{~nm}$ in thickness were cut using a Leica EM UC6 ultramicrotome equipped with a Leica EMFC6 cryocamera and a diamond blade. The thin samples thus obtained were deposited onto the copper grids.

$X$-ray powder diffraction (XRD) patterns were recorded in the $2-70^{\circ} 2 \theta$ range at steps of $0.05^{\circ}$ and a counting time of $5 \mathrm{~s} / \mathrm{step}$ on a Philips PW 1050 diffractometer, equipped with a $\mathrm{Cu}$ tube and a scintillation detector beam. The X-ray generator worked at $40 \mathrm{kV}$ and $30 \mathrm{~mA}$. The instrument resolution (divergent and antiscatter slits of $0.5^{\circ}$ ) was determined using standards free from the effect of reduced crystallite size and lattice defects. Diffraction patterns were analysed according to the Rietveld method [21] using the programme MAUD [22].

The ${ }^{13} \mathrm{C}\left\{{ }^{1} \mathrm{H}\right\}$ CP-MAS NMR spectra were obtained at room temperature with a Bruker Avance II $400 \mathrm{MHz}$ (9.4 T) spectrometer operating at $100.63 \mathrm{MHz}$ for the ${ }^{13} \mathrm{C}$ nucleus with an MAS rate of $10 \mathrm{kHz}, 400$ scans, a contact time of $1.5 \mathrm{~s}$ and a repetition delay of 2 s. Optimization of the Hartmann-Hahn condition [23] was obtained using an adamantine sample. Each sample was placed in a $4 \mathrm{~mm}$ zirconia rotor with KEL-F caps using silica as filler to avoid inhomogeneities inside the rotor. The proton spin-lattice relaxation time in the rotating frame $T_{1 \rho}(\mathrm{H})$ was indirectly determined, with the variable spin lock (VSL) pulse sequence, by carbon nucleus observation using a $90^{\circ}-\tau$-spin-lock pulse sequence prior to crosspolarization [24]. The data acquisition was performed by ${ }^{1} \mathrm{H}$ decoupling with a delay time, $\tau$, ranging from 0.1 to $7.5 \mathrm{~ms}$ and 
Table 1

Elemental analysis of calcined powders.

\begin{tabular}{llll}
\hline Sample & Nitrogen/wt.\% & Carbon/wt.\% & Hydrogen/wt.\% \\
\hline Un-calcined & 1.05 & 1.57 & 0.86 \\
Titania treated & 1.08 & 0.92 & 1.02 \\
$\quad$ at $200{ }^{\circ} \mathrm{C}$ & & & \\
$\begin{array}{l}\text { Titania treated } \\
\quad \text { at } 600{ }^{\circ} \mathrm{C}\end{array}$ & 0.28 & 0.15 & - \\
\hline
\end{tabular}

a contact time of $1.5 \mathrm{~ms}$. The $T_{\mathrm{CH}}$ values for all the carbon signals of PMMA were obtained through variable contact time (VCT) experiments [25]. The contact times used in the (VCT) experiments were $0.05,0.1,0.2,0.3,0.4,0.5,0.6,0.8,1.0,1.2,1.5,2.0,2.5,3.0,3.5,4.0$, $4.5,5.0,6.0$ and $7.0 \mathrm{~ms}$. The proton spin-lattice relaxation time in the laboratory frame $T_{1}(\mathrm{H})$ was determined, with the saturation recovery pulse sequence [26], by the carbon nucleus observation using a $90^{\circ}-\tau-90^{\circ}$ pulse sequence prior to cross polarization with a delay time $\tau$ ranging from 0.01 to $3 \mathrm{~s}$.

The dynamic mechanical analysis (DMA) of the composites were performed from 40 to $180^{\circ} \mathrm{C}$ in the bending mode at a heating rate of $5{ }^{\circ} \mathrm{C} \mathrm{min}-1$ and a frequency of $1 \mathrm{~Hz}$ using a Perkin Elmer Diamond DMA (Waltham, Massachusetts, U.S.A.).

Thermogravimetric analysis (TGA) was performed in a Perkin Elmer TGA7 (Waltham, Massachusetts, U.S.A.). The analyses were done under flowing nitrogen at a constant flow rate of $20 \mathrm{~mL} \mathrm{~min}^{-1}$. Samples (5-10 mg) were heated from 25 to $600{ }^{\circ} \mathrm{C}$ at heating rates of 3, 5, 7 and $9{ }^{\circ} \mathrm{C} \mathrm{min}^{-1}$. The degradation kinetics analyses were done using the following two methods [27]. The Flynn-Wall-Ozawa method is an isoconversional linear method based on the equation:

$\ln \beta=c-1.052 \frac{E_{a}}{R T}$

where $\beta$ = heating rate in $\mathrm{K} \mathrm{min}^{-1}, c$ is a constant, $E_{a}=$ activation energy in $\mathrm{kJ} \mathrm{mol}^{-1}, R=$ universal gas constant, and $T=$ temperature in K. The plot of $\log \beta$ vs. $1 / T$, obtained from the TGA curves recorded at several heating rates, should be a straight line. The activation energy can be evaluated from its slope. The second method is Kissinger-Akahira-Sunose which it is based on the equation,

$\ln \left(\frac{\beta}{T^{2}}\right)=\ln \left(\frac{A R}{E_{a} \cdot g(\alpha)}\right)-\frac{E_{a}}{R T}$

where $\alpha=$ fraction of conversion (defined as mass loss at respective temperature), $A=$ pre-exponential factor and $g(\alpha)=$ algebraic expression for integral methods. From the TGA curves recorded at different heating rates $\beta$, temperatures $T$ were determined at the conversions $\alpha=10 \%-90 \%$. The activation energies were calculated from the slope of the straight lines of $\operatorname{In}\left(\beta / T^{2}\right.$ versus $1 / T$.

The TGA-FTIR analyses were performed in a Perkin Elmer STA6000 simultaneous thermal analyser (Waltham, Massachusetts, U.S.A.). The analyses were done under flowing nitrogen at a constant flow rate of $20 \mathrm{~mL} \mathrm{~min}{ }^{-1}$. Samples $(20-25 \mathrm{mg}$ ) were heated from 30 to $600{ }^{\circ} \mathrm{C}$ at $10{ }^{\circ} \mathrm{C} \mathrm{min}-1$ and held for $4 \mathrm{~min}$ at $600{ }^{\circ} \mathrm{C}$. The furnace was linked to the FTIR (Perkin Elmer Spectrum 100 , Waltham, Massachusetts, U.S.A.) with a gas transfer line. The volatiles were analysed over a $400-4000 \mathrm{~cm}^{-1}$ wavenumber range at a resolution of $4 \mathrm{~cm}^{-1}$. The FTIR spectra of the volatiles emitted at different temperatures during the degradation process were recorded in the transmittance mode.

\section{Results and discussion}

\subsection{Elemental analysis}

The elemental analysis performed on the powders shows that nitrogen, carbon and hydrogen were present in the powders due to an incomplete combustion reaction between the glycine and the nitrate (Table 1). Their quantities were low and decreased at higher temperatures. The presence of carbon explains the black colour of the powders treated at $200{ }^{\circ} \mathrm{C}$.

\section{2. $X$-ray diffraction $(X R D)$}

The XRD patterns of the $\mathrm{TiO}_{2}$ powder treated at $200{ }^{\circ} \mathrm{C}$ and $600{ }^{\circ} \mathrm{C}$, pure PMMA, and their respective composites containing 2 and $5 \mathrm{wt}$.\% of fillers are shown in Fig. 1. The peak profile of the $\mathrm{TiO}_{2}$ powder treated at $200{ }^{\circ} \mathrm{C}$ is very broad, thus accounting for the nanocrystalline condition of the materials with, probably, a large lattice disorder. Rietveld analysis [21] of the spectrum has been performed on the XRD patterns of the two powders. The sample treated at $200{ }^{\circ} \mathrm{C}$ is constituted of a pure anatase phase [S.G. $14_{1} /$ amd, $a=3.771( \pm 1) \AA$ and $c=9.484( \pm 1) \AA, Z=4$ ] with an average crystallite size of ca $640 \pm 20 \AA$, while the powder treated at $600{ }^{\circ} \mathrm{C}$ is described in terms of two crystalline phases: $99 \pm 1 \mathrm{wt} . \%$ of tetragonal rutile [S.G. P42/mnm, $a=4.5933( \pm 1) \AA$ and $c=2.9592 \pm 1 \AA$, average crystallite size $1070 \pm 20 \AA$ and $2 \pm 1 \mathrm{wt} . \%$ of orthorhombic brookite [S.G. Pcab, $a=5.4558( \pm 1) \AA$, $b=9.1819( \pm 1) \AA$ and $c=5.1429( \pm 1) \AA$, average crystallite size $200 \pm 10 \AA ̊$ ]. In both powders a small quantity of amorphous carbon is present.
A

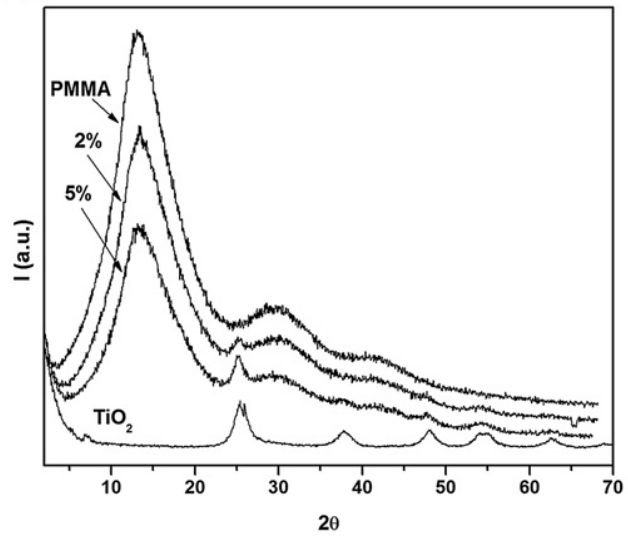

B

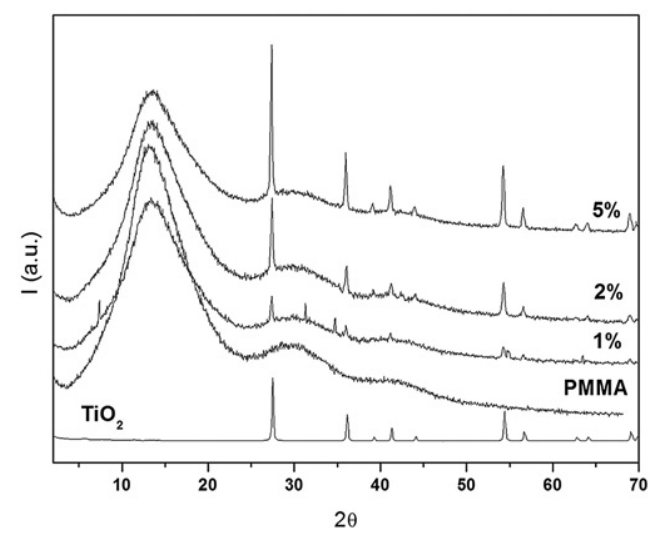

Fig. 1. (A) XRD patterns of $\mathrm{TiO}_{2}$ powder treated at $200{ }^{\circ} \mathrm{C}$, pure PMMA, and $\mathrm{PMMA}-\mathrm{TiO}_{2}$ nanocomposites containing 2 and 5 wt.\% of TiO ${ }_{2}$, and $(\mathrm{B}) \mathrm{XRD}$ patterns of $\mathrm{TiO}{ }_{2}$ powder treated at $600{ }^{\circ} \mathrm{C}$, pure PMMA, and $\mathrm{PMMA}-\mathrm{TiO}_{2}$ nanocomposites containing 2 and $5 \mathrm{wt} . \%$ of $\mathrm{TiO}_{2}$. 

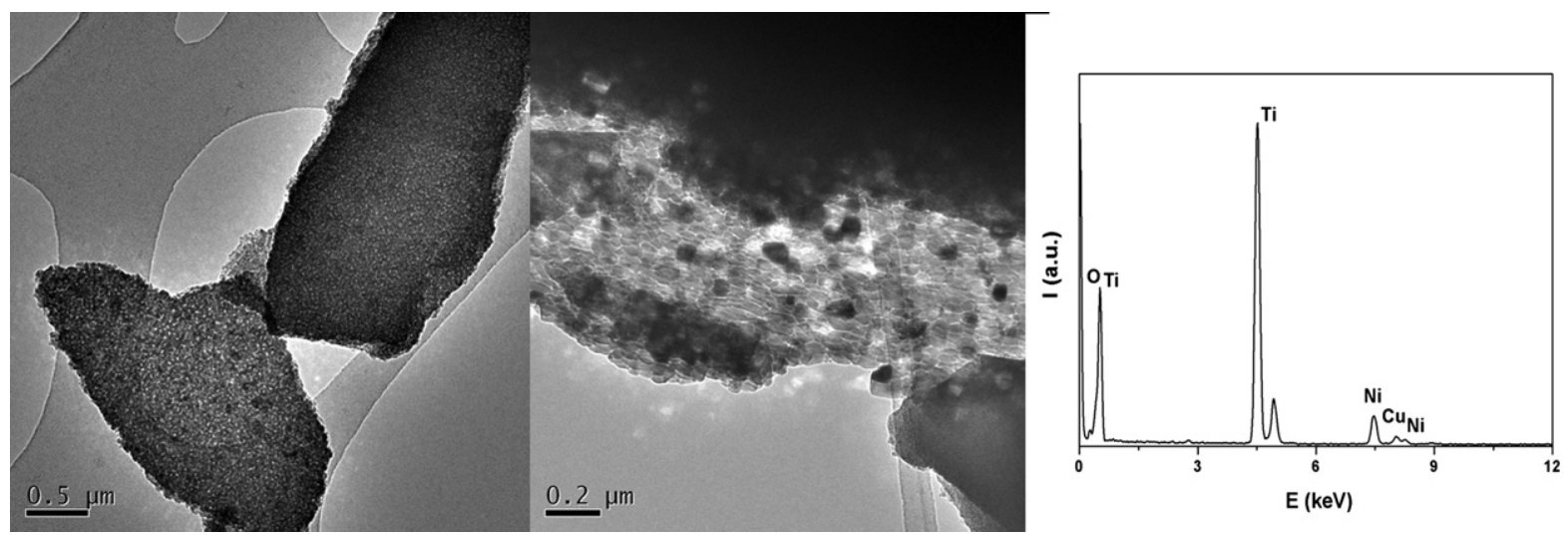

Fig. 2. TEM micrographs of the $\mathrm{TiO}_{2}$ (anatase) powder.

The diffraction pattern of PMMA shows a broad diffraction peak at $2 \theta=14^{\circ}$, typical of an amorphous material, together with two bands of lower intensities centred at $29.7^{\circ}$ and $41.7^{\circ}$. The XRD spectrum of the nanocomposites shows the bands observed in PMMA together with the peaks of the fillers, the intensity of which increases with increasing quantity. This confirms that the filler maintained its structure in the composite, and that the orientation of the PMMA chains was also not influenced during the nanocomposite preparation process as occurred in other composites [28].

\subsection{Transmission electron microscopy (TEM)}

Some TEM micrographs of the anatase and rutile titania powders are reported in Figs. 2 and 3, respectively. The anatase titania is constituted of aggregates with sizes between 0.5 and 1 micron. The aggregates are formed by several particles of about $20 \mathrm{~nm}$ diameter very densely packed. The EDS spectrum of anatase titania, in Fig. 2, shows the characteristic peaks of $\mathrm{Ti}$ and $\mathrm{O}$ of the sample, together with copper of the grid. The rutile titania is constituted of particles with sizes between 1 and 2 micron. The particles were formed by several irregular smaller particles of about 50-100 nm diameter very densely packed.

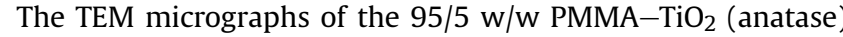
and $95 / 5 \mathrm{w} / \mathrm{w}$ PMMA-TiO 2 (rutile) nanocomposites are reported in Figs. 4 and 5 , respectively. The $\mathrm{PMMA}^{-\mathrm{TiO}_{2}}$ (anatase) nanocomposite is constituted of spongy aggregates of about 0.5 microns composed of smaller particles of $\mathrm{TiO}_{2}$. The $\mathrm{PMMA}^{-\mathrm{TiO}_{2}}$ (rutile) nanocomposite is constituted of particles of about $100 \mathrm{~nm}$ that form aggregates irregular in shape like that observed in the powder. The observed nanoparticles are similar in size to those of the used powder. In both cases the particles were well dispersed, but there were clear indications of nanoparticle agglomeration which are smaller in the rutile titania containing PMMA.

\subsection{Nuclear magnetic resonance (NMR) spectroscopy}

${ }^{13} \mathrm{C}\left\{{ }^{1} \mathrm{H}\right\}$ CP-MAS NMR spectra of PMMA and of the composites having 5 wt.\% of filler are reported in Fig. 6. Five peaks are present in all the spectra. According to literature [29] peak 1 at $17 \mathrm{ppm}$ is related to the methyl group, peak 2 at $45 \mathrm{ppm}$ is related to the methylene group, peak 3 at $52 \mathrm{ppm}$ is related to the quaternary carbon of the polymeric chain, peak 4 at $56 \mathrm{ppm}$ is related to the methoxyl group and peak 5 at 177 ppm is related to the carbonyl carbon. No modification in the chemical shift and in the band shape is observed after composite formation, indicating that no chemical modification occurred in the polymer.

The spin-lattice relaxation time in the laboratory frame $T_{1}(\mathrm{H})$ and in the rotating frame $T_{1 \rho}(\mathrm{H})$ and the cross-polarization time $T_{\mathrm{CH}}$ were determined through solid-state NMR measurements in order to evaluate the dynamic modifications occurring in the polymeric chain of the PMMA matrix after composite formation. The $T_{1}(\mathrm{H})$, $T_{1 \rho}(\mathrm{H})$, and $T_{\mathrm{CH}}$ values obtained from each peak in the ${ }^{13} \mathrm{C}$ spectra of all the samples are reported in Table 2 . The presence of the fillers in

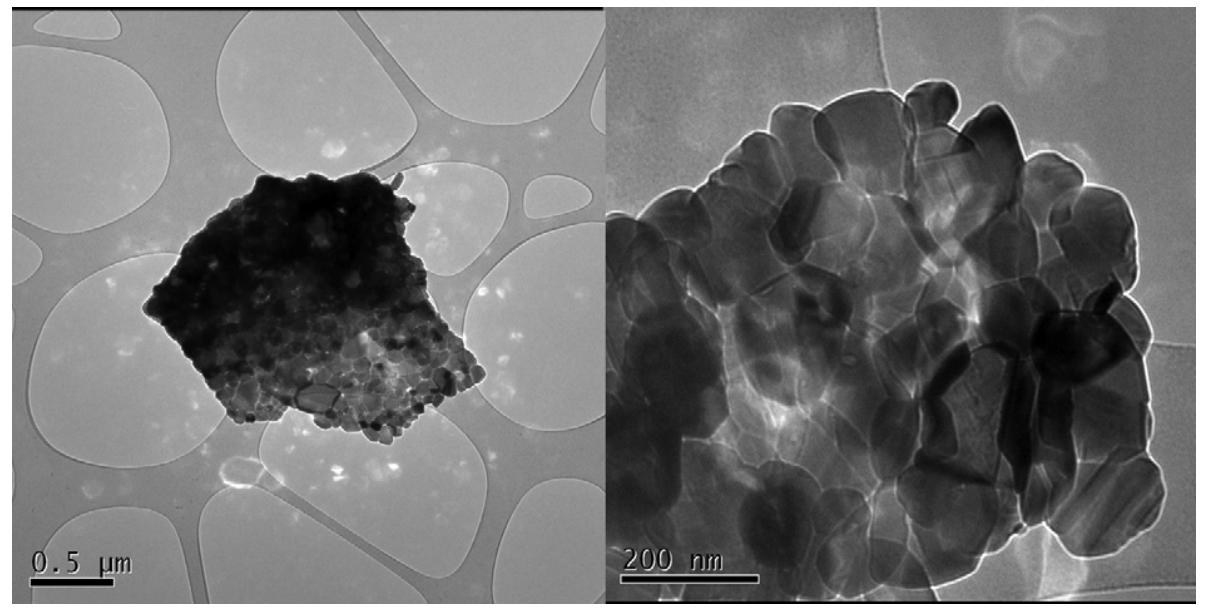

Fig. 3. TEM micrographs of the $\mathrm{TiO}_{2}$ (rutile) powder. 


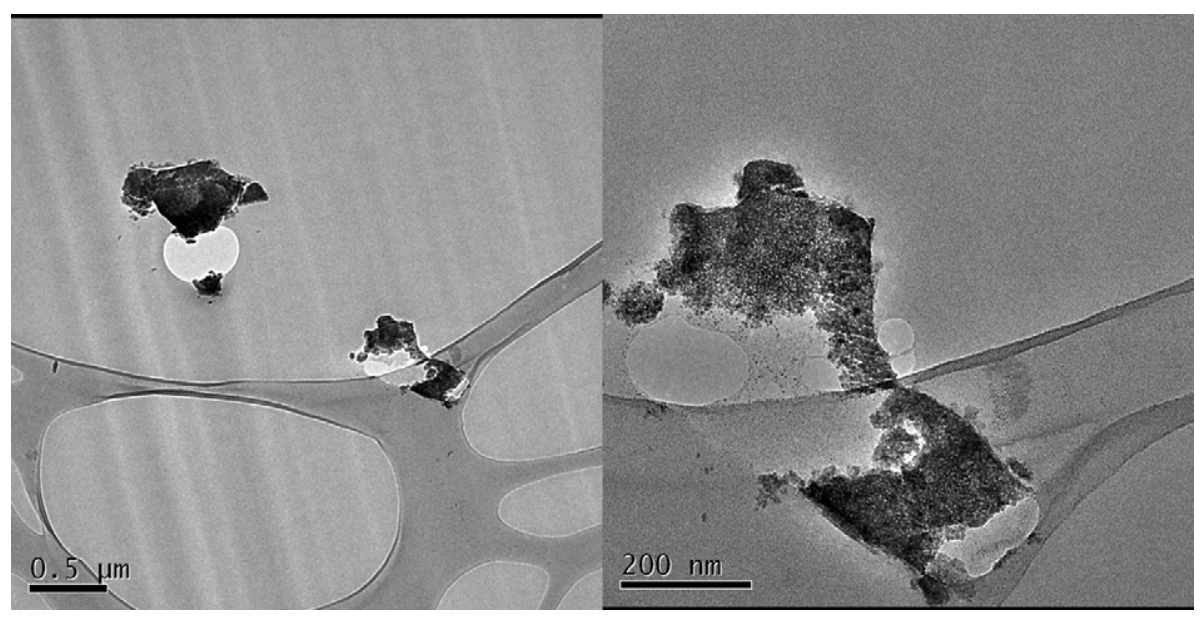

Fig. 4. TEM micrographs of the $95 / 5 \mathrm{w} / \mathrm{w} \mathrm{PMMA}^{-\mathrm{TiO}_{2}}$ (anatase) composite.

the PMMA matrix slightly modifies only the $T_{1}(\mathrm{H})$ values for the $\mathrm{PMMA}^{-\mathrm{TiO}_{2}}$ (rutile) having $5 \mathrm{wt}$.\% of $\mathrm{TiO}_{2}$. This indicates that the materials were dynamically homogeneous in a range from tens to hundreds of nanometres. An increase in $T_{1 \rho}(\mathrm{H})$ values was observed for the $\mathrm{PMMA}^{-\mathrm{TiO}_{2}}$ (anatase) composite. In particular, the bigger effect involved the carbonyl carbons. The presence of rutile $\mathrm{TiO}_{2}$ did not significantly affect the $T_{1 \rho}(\mathrm{H})$ values. The $T_{1 \rho}(\mathrm{H})$ parameter is inversely proportional to the spectral density of motion in the $\mathrm{kHz}$ frequency region which reflects the dynamic behaviour of a polymeric chain in a range of a few nanometres. Larger $T_{1 \rho}(\mathrm{H})$ values result from an increase in the stiffness of a polymer.

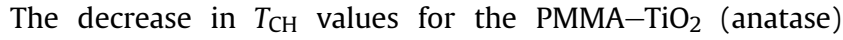
composite indicates that there is an increase in the heteronuclear dipolar interactions between the carbons and the surrounding hydrogen nuclei. This is evidence that the presence of the anatase $\mathrm{TiO}_{2}$ into the PMMA matrix made the polymer structure more rigid. This rigidity increase favoured the cross polarization mechanism yielding smaller $T_{\mathrm{CH}}$ values. The presence of rutile $\mathrm{TiO}_{2}$ in PMMA gave rise to similar, but less intense, effects.

\subsection{Dynamic mechanical analysis (DMA)}

The storage modulus of the pure PMMA, as well as those of PMMA-TiO 2 (anatase) and $\mathrm{PMMA}^{-\mathrm{TiO}_{2}}$ (rutile) composites having 1,2 and 5 wt.\% of $\mathrm{TiO}_{2}$, are reported in Figs. 7 and 8. The presence of anatase $\mathrm{TiO}_{2}$ does not show much influence on the storage and loss modulus at lower temperatures, but these values are observably higher above the glass transition (Fig. 7a and b). This suggests that the particles immobilized the polymer chains at higher temperatures, probably due to the increase in rigidity (as observed from the NMR results), although the higher carbon content in the particles could also have played a role. Fig. 8 a shows that 1 and $2 \%$ rutile $\mathrm{TiO}_{2}$ reduced the storage modulus values between 40 and $90{ }^{\circ} \mathrm{C}$, probably because of a plasticizing effect of the titania nanoparticles on the PMMA matrix (the TEM results show less agglomeration in the case of the rutile titania nanoparticles), while $5 \mathrm{wt}$.\% rutile $\mathrm{TiO}_{2}$ increased the storage modulus above the glass transition. It seems as if effective immobilization of the polymer chains only takes place at higher rutile titania content, which is in line with the NMR results that indicated less intense interaction between PMMA and rutile titania. The loss modulus curves follow the same trend (Fig. 8b). Whatever the reason for the increased storage modulus, the difference in carbon content between the rutile and anatase phases, as confirmed through elemental analysis, could also have contributed to the differences in modulus.

The glass transition temperature of PMMA generally increased in the anatase titania containing nanocomposites (Fig. 7c). In the nanocomposites containing rutile titania, only the composite with $5 \%$ rutile titania showed a significant increase in the glass transition temperature. These results were unexpected compared to the NMR results, which suggested strong interaction between anatase titania and PMMA. Although these results and the $T_{\mathrm{CH}}$ values obtained by

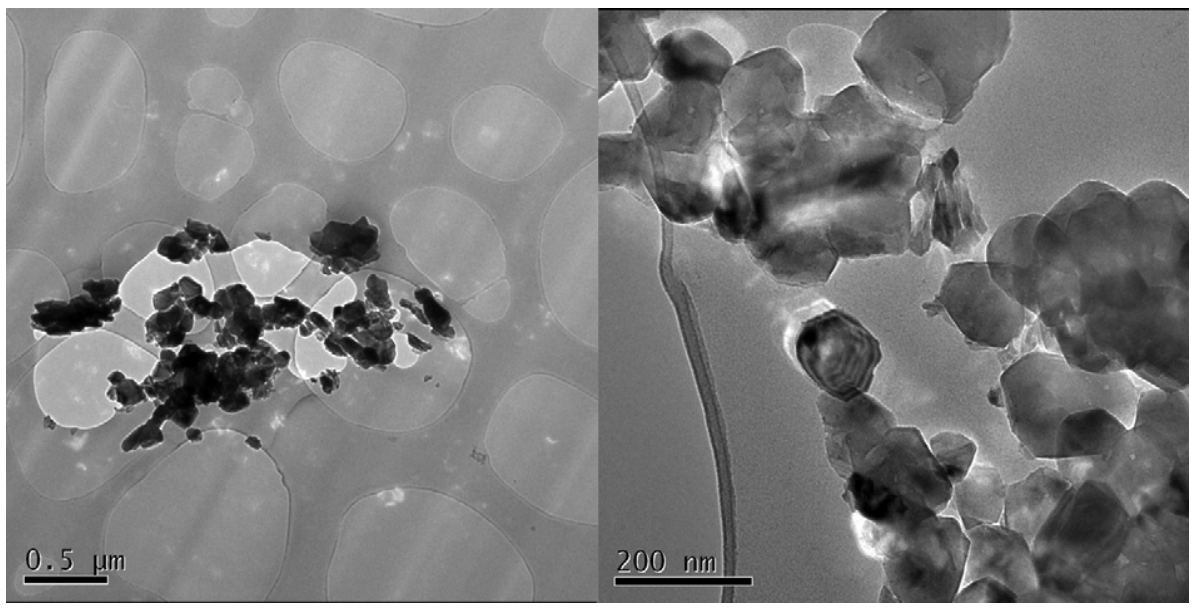

Fig. 5. TEM micrographs of the $95 / 5 \mathrm{w} / \mathrm{w}$ PMMA-TiO 2 (rutile) composite. 


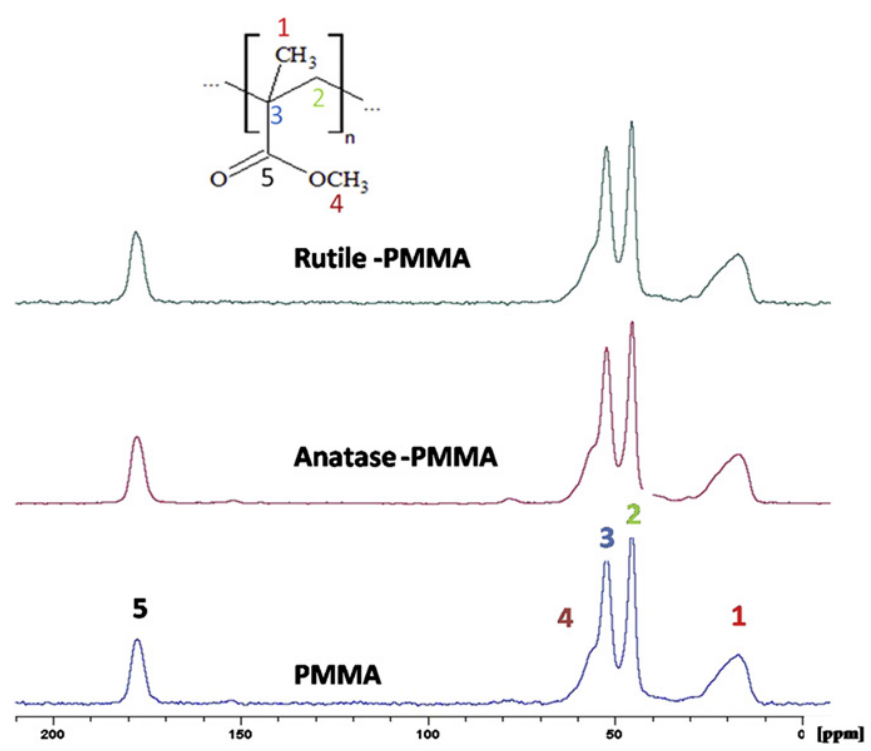

Fig. 6. ${ }^{13} \mathrm{C}\left\{{ }^{1} \mathrm{H}\right\}$ CP-MAS NMR spectra of PMMA, PMMA-TiO ${ }_{2}$ (anatase) and PMMA-TiO 2 (rutile).

NMR do not seem to support each other, it should be realized that the $T_{\mathrm{CH}}$ values reflect the dipolar interactions within a nanometre scale and can therefore not be strictly correlated with the bulk thermal mechanical properties. On the other hand, the $T_{1} \mathrm{H}$ relaxation time values, which describe the dynamic behaviour of macromolecules within a larger scale, are slightly higher for the 95/ $5 \mathrm{w} / \mathrm{w}$ PMMA-TiO 2 (rutile) than for those of the neat PMMA and the $\mathrm{PMMA}-\mathrm{TiO}_{2}$ (anatase) samples, suggesting an increase in matrix stiffness which is in line with the DMA results.

\subsection{Thermogravimetric analysis (TGA)}

The TGA curves of all the samples are reported in Fig. 9. They all show a single-step degradation and an increase in char content with an increase in the titania amount. The degradation temperatures for the anatase titania system slightly moves to higher values with increasing nanoparticle content, whereas there was no significant change for the rutile titania system. This could be related to the interaction between the anatase titania and PMMA, according to NMR findings, which led to immobilization of free radical chains formed during degradation and/or hindering of the diffusion of volatile decomposition products. The results support the NMR observation in which the presence of anatase titania showed a more significant influence on polymer chain mobility than the rutile titania. Different authors suggested different mechanisms for the thermal stability improvement. Wang et al. [1], in their study of PMMA/silica/zirconia nanocomposites, explained the improvement in thermal stability as being the result of the formation of networks of polymer chains and inorganic moieties which may restrain the movement of free radicals. In another study on PMMA/titania
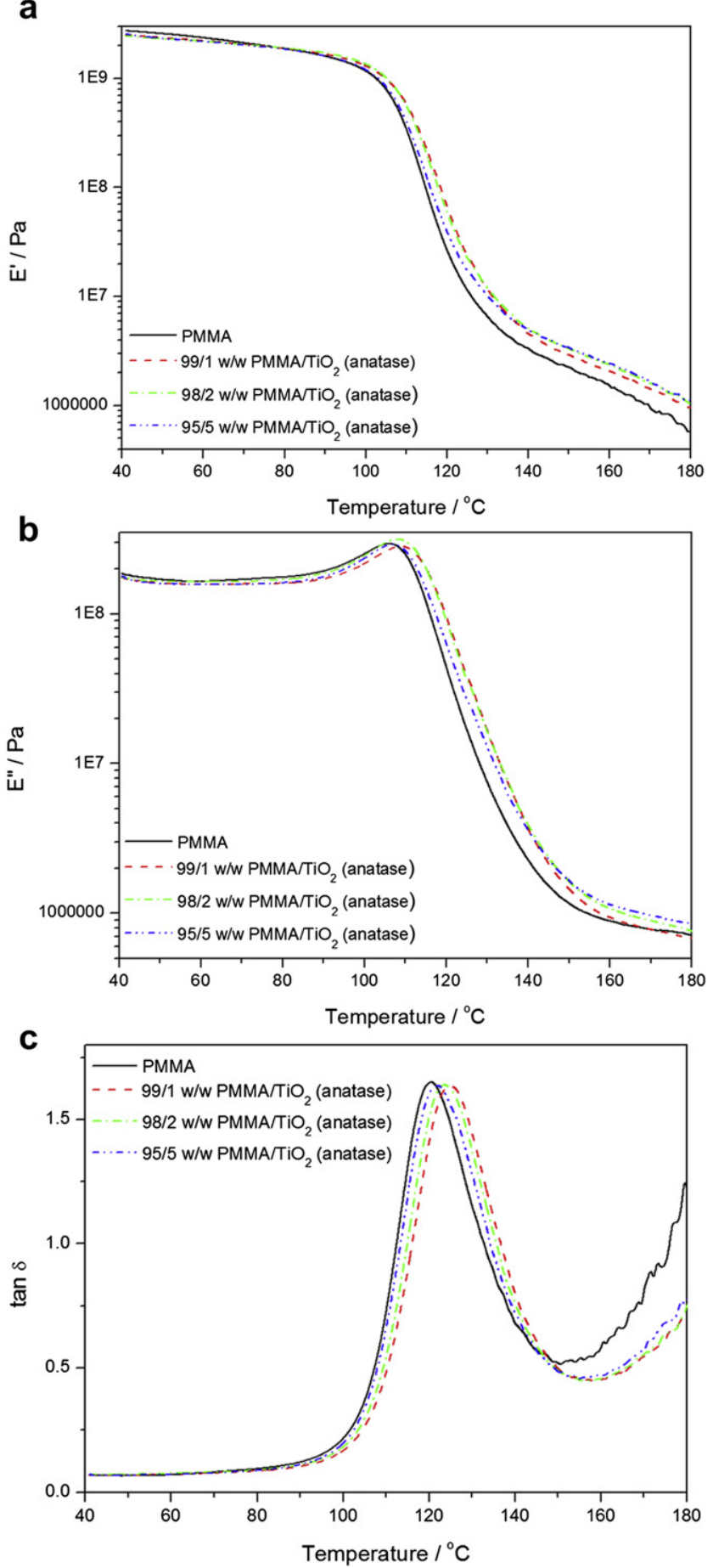

Fig. 7. (a) Storage modulus, (b) loss modulus and (c) tan $\delta$ curves of PMMA and PMMA- $\mathrm{TiO}_{2}$ (anatase) nanocomposites.

Table 2

Relaxation time values for all the peaks in the ${ }^{13} \mathrm{C}$ spectra of the PMMA and the two composites having $5 \mathrm{wt} \%$ of filler.

\begin{tabular}{|c|c|c|c|c|c|c|c|c|c|}
\hline \multirow[t]{2}{*}{ ppm } & \multicolumn{3}{|l|}{$T_{1} \mathrm{H}(\mathrm{s})$} & \multicolumn{3}{|l|}{$T_{1 \rho} \mathrm{H}(\mathrm{ms})$} & \multicolumn{3}{|l|}{$T_{\mathrm{CH}}(\mu \mathrm{s})$} \\
\hline & PMMA & $\begin{array}{l}\text { Anatase- } \\
\text { PMMA }\end{array}$ & $\begin{array}{l}\text { Rutile- } \\
\text { PMMA }\end{array}$ & PMMA & $\begin{array}{l}\text { Anatase- } \\
\text { PMMA }\end{array}$ & $\begin{array}{l}\text { Rutile- } \\
\text { PMMA }\end{array}$ & PMMA & $\begin{array}{l}\text { Anatase- } \\
\text { PMMA }\end{array}$ & $\begin{array}{l}\text { Rutile-- } \\
\text { PMMA }\end{array}$ \\
\hline 178 & $0.70 \pm 0.02$ & $0.67 \pm 0.01$ & $0.74 \pm 0.01$ & $18.1 \pm 0.5$ & $24.7 \pm 0.6$ & $17.2 \pm 0.6$ & $1306 \pm 167$ & $971 \pm 95$ & $1053 \pm 95$ \\
\hline 56 & $0.71 \pm 0.03$ & $0.68 \pm 0.02$ & $0.72 \pm 0.02$ & $20.4 \pm 0.9$ & $24.1 \pm 0.9$ & $20.3 \pm 0.9$ & $254 \pm 79$ & $126 \pm 14$ & $112 \pm 20$ \\
\hline 52 & $0.71 \pm 0.01$ & $0.68 \pm 0.01$ & $0.70 \pm 0.01$ & $16.2 \pm 0.2$ & $19.8 \pm 0.1$ & $20.4 \pm 0.1$ & $339 \pm 42$ & $275 \pm 27$ & $285 \pm 21$ \\
\hline 45 & $0.71 \pm 0.01$ & $0.67 \pm 0.01$ & $0.69 \pm 0.01$ & $17.0 \pm 0.2$ & $20.1 \pm 0.1$ & $19.2 \pm 0.1$ & $614 \pm 33$ & $375 \pm 22$ & $652 \pm 17$ \\
\hline 17 & $0.71 \pm 0.01$ & $0.66 \pm 0.01$ & $0.69 \pm 0.01$ & $19.3 \pm 0.4$ & $22.7 \pm 0.3$ & $17.1 \pm 0.3$ & $320 \pm 36$ & $269 \pm 21$ & $328 \pm 16$ \\
\hline
\end{tabular}


a

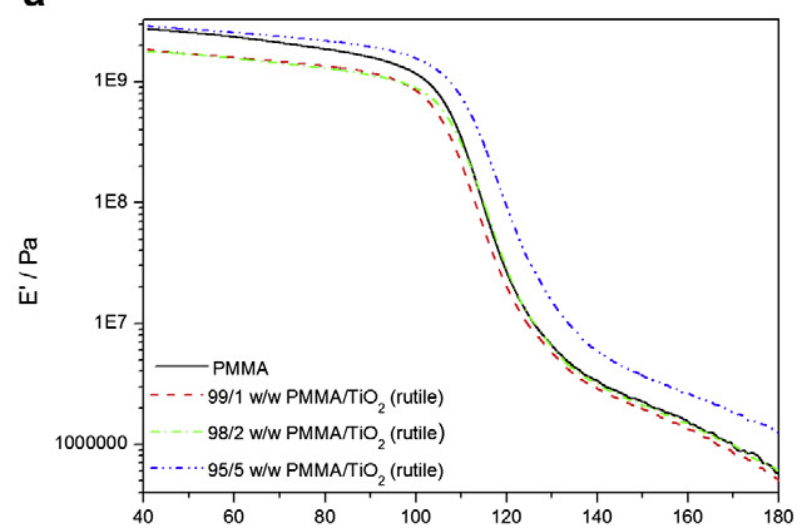

b
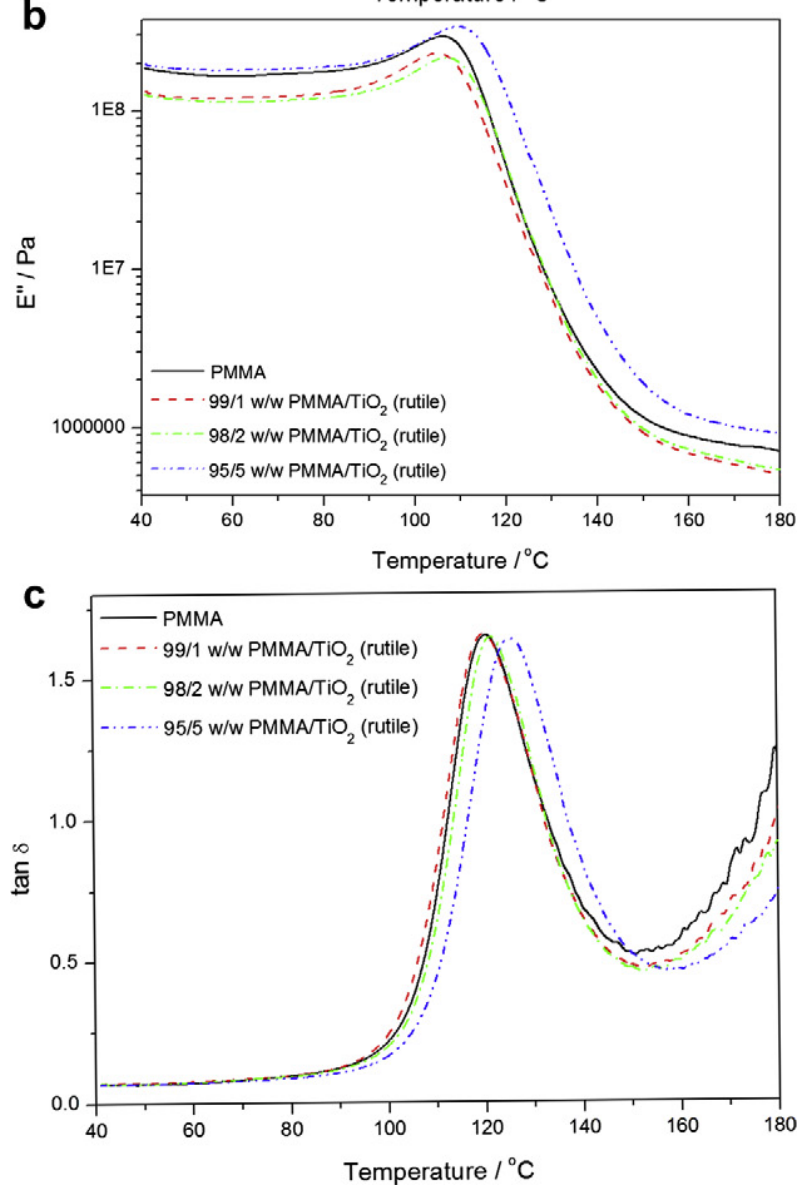

Fig. 8. (a) Storage modulus, (b) loss modulus and (c) tan $\delta$ curves of PMMA and PMMA- $\mathrm{TiO}_{2}$ (rutile) nanocomposites.

nanocomposites [30] they confirmed their view of radical trapping being the main degradation stabilization mechanism. However, Laachachi et al. [31] proposed the restriction of polymer chain mobility as the mechanism for improvement in thermal stability. It therefore seems as if the issue has not been resolved yet, and it is quite possible that the improvement in thermal stability may be the result of a combination of radical trapping and polymer chain immobilization.

The isoconversional graphs of $\ln \beta$ versus $1 / T$ and $\ln \left(\beta / T^{2}\right)$ versus $1 / T$ were plotted from the TGA curves of PMMA, 95/5 w/w PMMA-titania (anatase) and 95/5 w/w PMMA-titania (rutile) at heating rates of $3,5,7$ and $9{ }^{\circ} \mathrm{C} \min ^{-1}$. The activation energy values
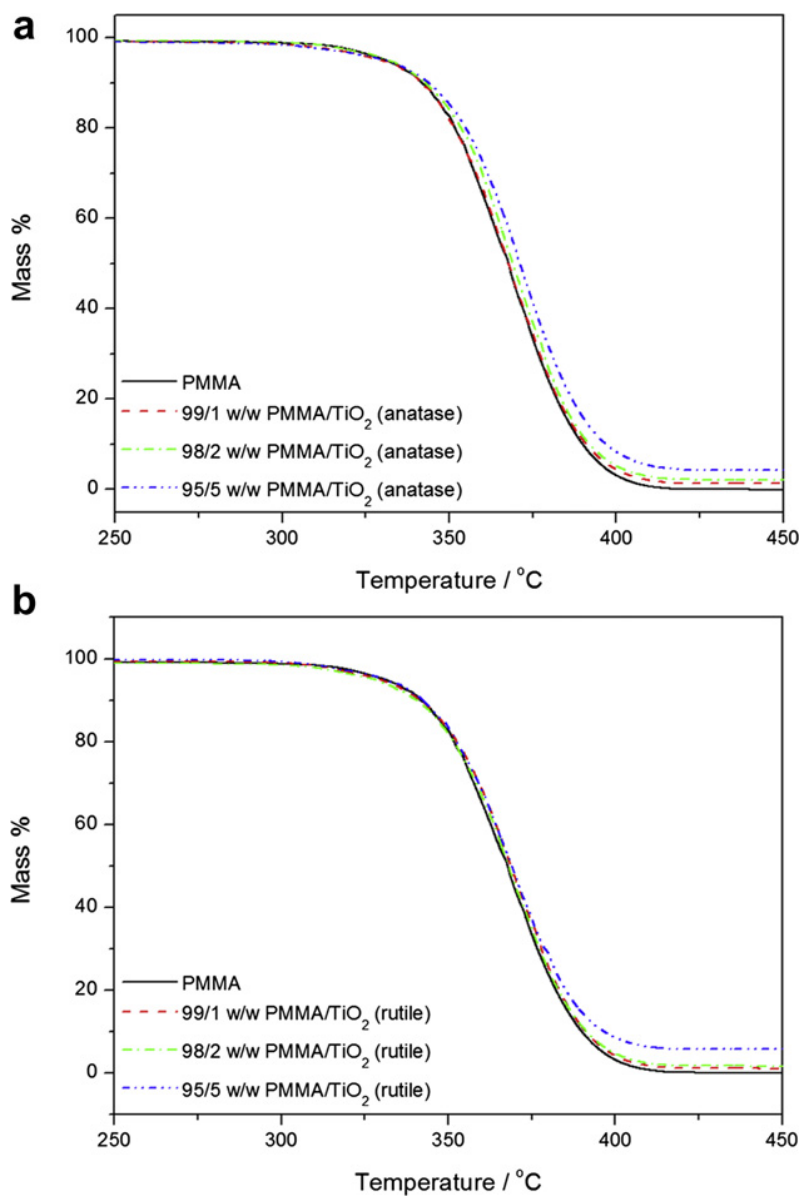

Fig. 9. TGA curves of PMMA, and of (a) $P M M A-\mathrm{TiO}_{2}$ (anatase) and (b) PMMA-TiO (rutile) nanocomposites.

were calculated from the slopes of the isoconversional plots according to Equations (1) and (2). Both isoconversional methods gave similar values of the activation energies within experimental uncertainty. The relationship between the activation energies and the degree of conversion is reported in Fig. 10. These values fall within the range of activation energies for PMMA degradation reported previously $[32,33]$. The activation energy values of pure

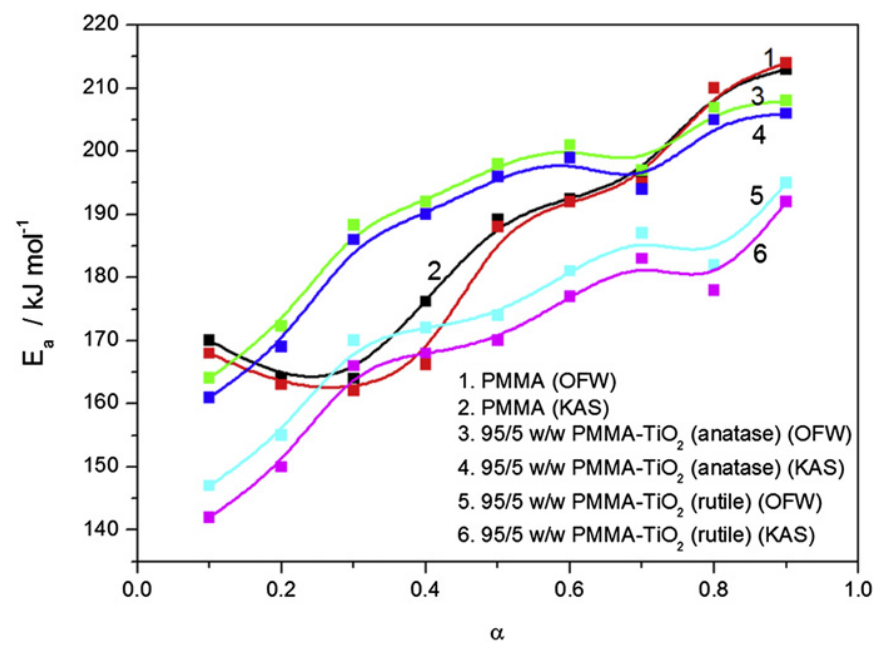

Fig. 10. $E_{\mathrm{a}}$ values as function of extent of degradation obtained by the OFW and KAS methods. 


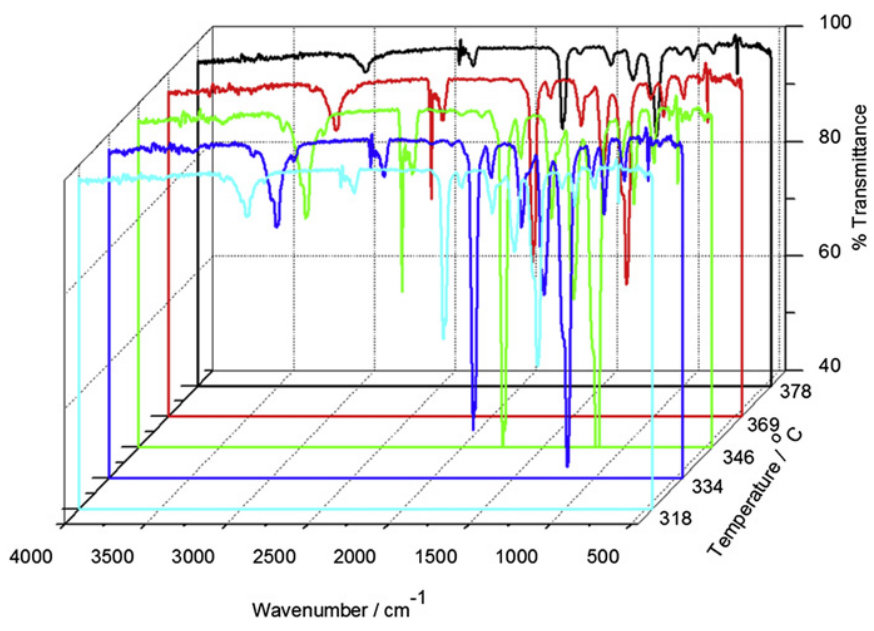

Fig. 11. FTIR curves at different temperatures during the thermal degradation of PMMA.

PMMA and its nanocomposites generally showed an increase with the degree of conversion. The increase in activation energy with an increase in degree of conversion during the degradation of polymers was observed and explained in several papers [32-34]. Gao et al. [33] gave an acceptable explanation for the change in activation energy with increasing degree of degradation for PMMA. They linked this observation to a change in reaction order which may have been brought about by a change in degradation mechanism from a first-order unzipping reaction to a higher order chain scission reaction.

The presence of anatase titania shows higher activation energy of degradation values between 20 and $70 \%$ weight loss than those of PMMA. The observation supports the increase in thermal stability of the $\mathrm{PMMA}-\mathrm{TiO}_{2}$ (anatase) nanocomposites observed in TGA. However, the presence of the rutile phase generally shows lower activation energy of degradation values. The decreased activation energy suggests that rutile titania may have acted as a catalyst for the thermal decomposition of the composites. Although the differences between the anatase and rutile titania phases (summarized in the 'Introduction' section) indicate that the anatase phase should have had a more significant catalytic effect, the differences in carbon contents in the two phases as well as the

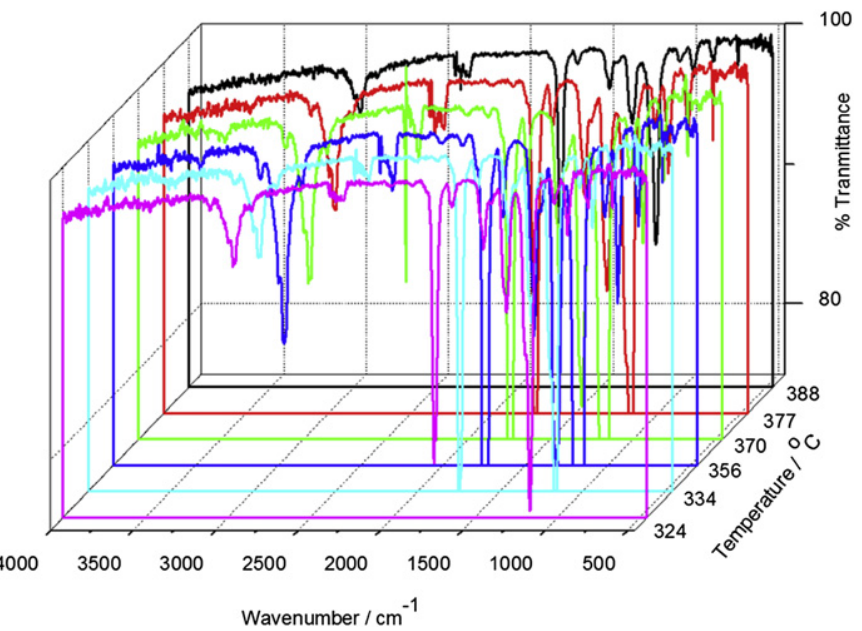

Fig. 12. FTIR curves at different temperatures during the thermal degradation of 95/ $5 \mathrm{w} / \mathrm{w}$ PMMA- $\mathrm{TiO}_{2}$ (anatase).

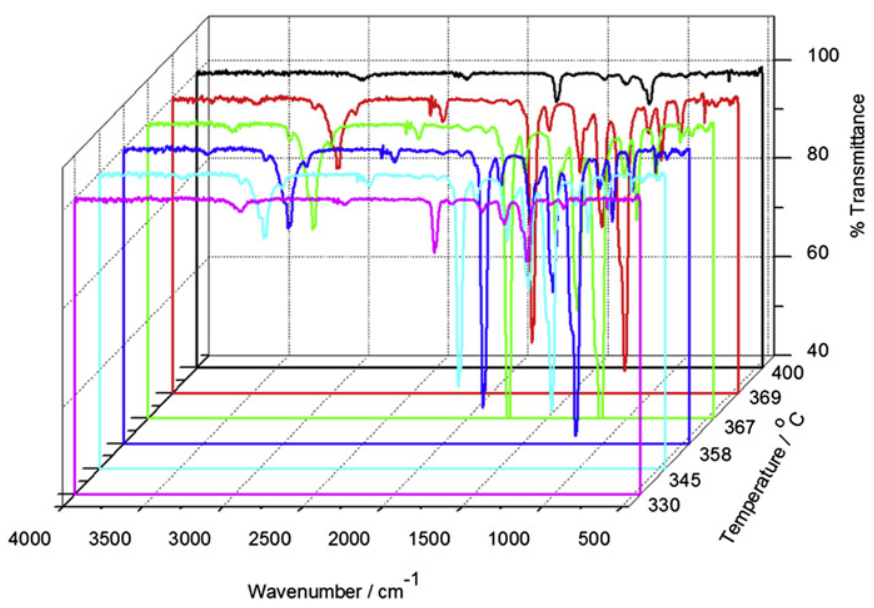

Fig. 13. FTIR curves at different temperatures during the thermal degradation of 95/5 w/w PMMA-TiO 2 (rutile).

lower extent of agglomeration in the case of rutile titania may have contributed to the latter having a more significant catalytic effect.

TGA-FTIR analyses were done to establish the nature of the degradation product(s), and to confirm the observations from the kinetic analysis of the thermal degradation process of PMMA and 95/5 w/w PMMA-titania. All the spectra almost perfectly match the known spectrum of methyl methacrylate (MMA), which confirms the primary degradation as that of de-polymerization (Figs. 11-14). The peak around $2966 \mathrm{~cm}^{-1}$ is assigned to the $\mathrm{CH}_{3}$ and $\mathrm{CH}_{2}$ stretching vibrations, whereas their bending vibration appeared around $1451 \mathrm{~cm}^{-1}$ for $\mathrm{CH}_{2}$ and $1314 \mathrm{~cm}^{-1}$ for $\mathrm{CH}_{3}$. The carbonyl absorption vibration appears around $1744 \mathrm{~cm}^{-1}$ and the stretching vibration for $\mathrm{C}-\mathrm{O}$ is around $1167 \mathrm{~cm}^{-1}$. The peak at around $2336 \mathrm{~cm}^{-1}$ is related to the asymmetric stretching mode of $\mathrm{CO}_{2}$. No new peaks or peak shifts were observed for the nanocomposite samples. There is a clear increase in peak intensity for all the characteristic peaks with increasing temperature, it reaches a maximum, and decreases again with further increase in temperature. It can be observed that at around $400{ }^{\circ} \mathrm{C}$ the peaks of PMMA and the $\mathrm{PMMA}-\mathrm{TiO}_{2}$ (rutile) nanocomposite start to disappear, while that of the $\mathrm{PMMA}^{-\mathrm{TiO}_{2}}$ (anatase) nanocomposite are still intense. It seems as if the volatilization of the degradation products is slower for the PMMA- $\mathrm{TiO}_{2}$ (anatase) nanocomposite, which implies more intimate contact between PMMA or MMA and

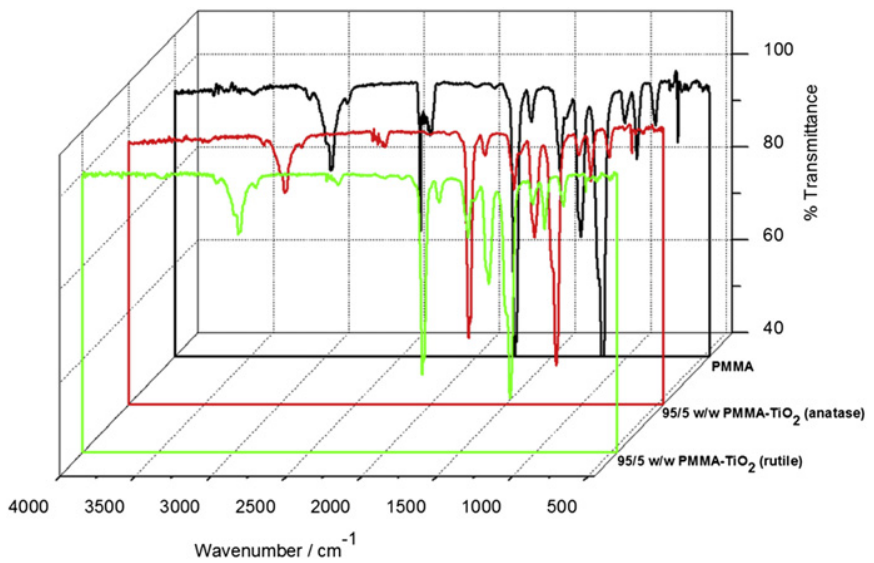

Fig. 14. FTIR curves obtained at $346{ }^{\circ} \mathrm{C}$ during the degradation of PMMA, 95/5 w/w $\mathrm{PMMA}^{-\mathrm{TiO}_{2}}$ (anatase) and 95/5 w/w PMMA-TiO 2 (rutile). 
anatase titania (Fig. 14). This supports the improved thermal stability and higher activation energy of the $\mathrm{PMMA}^{-\mathrm{TiO}_{2}}$ (anatase) nanocomposite compared to the $\mathrm{PMMA}^{-\mathrm{TiO}_{2}}$ (rutile) nanocomposite.

\section{Conclusions}

Two types of titania, anatase and rutile, were successfully prepared and their structures were confirmed by XRD. Elemental analysis showed the presence of different carbon contents in these two types of nanoparticles. PMMA-titania nanocomposites with both types of nanoparticles were prepared. TEM analysis showed that both rutile and anatase titania were well dispersed into the PMMA matrix (although that of rutile titania was slightly better) and did not change the amorphous structure of the PMMA. The fillers had different effects on the polymer chain mobility. NMR results showed different extents of interaction between PMMA and the two different types of titania. The two types of titania nanoparticles had slightly different influences on the thermomechanical properties of PMMA, as well as its degradation kinetics. These were probably the result of differences in particle size, extent of agglomeration, crystalline structure and carbon content. The quantification of the influence of these differences on the respective properties of the PMMA nanocomposites will be the subject of a separate study.

\section{Acknowledgements}

The authors would like to thank MIUR for supporting this research through the COOPERLINK 2009 Prot. CII098ZQLT "Sintesi e caratterizzazione di compositi polimetilmetacrilato e nano- $\mathrm{TiO}_{2} /$ $\mathrm{ZrO}_{2}$ ". The National Research Foundation in South Africa and the University of the Free State are acknowledged for financial support of the research.

\section{References}

[1] Wang H, Xu P, Zhong W, Shen L, Du Q. Transparent poly(methyl methacrylate)/silica/zirconia nanocomposites with excellent thermal stabilities. Polymer Degradation and Stability 2005;87:319-27. doi:10.1016/j. polymdegradstab.2004.08.015.

[2] $\mathrm{Hu} \mathrm{Y,} \mathrm{Gu} \mathrm{G,} \mathrm{Zhou} \mathrm{S,} \mathrm{Wu} \mathrm{L} \mathrm{Preparation} \mathrm{and} \mathrm{properties} \mathrm{of} \mathrm{transparent} \mathrm{PMMA/}$ $\mathrm{ZrO}_{2}$ nanocomposites using 2-hydroxyethyl methacrylate as a coupling agent. Polymer 2011;52:122-9. doi:10.1016/j.polymer.2010.11.020.

[3] Wang H, Xu P, Meng S, Zhong W, Du W, Du Q. Poly(methyl methacrylate)/ silica/zirconia nanocomposites with greatly improved thermal and ultraviolet-shielding properties. Polymer Degradation and Stability 2006;91: 1455-61. doi:10.1016/j.polymdegradstab.2005.10.008.

[4] Orban T, Isitman NA, Hacaloglu J, Kaynak C. Thermal degradation of organophosphorus flame-retardant poly(methyl methacrylate) nanocomposites containing nanoclay and carbon nanotubes. Polymer Degradation and Stability 2012;97:273-80. doi:10.1016/j.polymdegradstab.2011.12.020.

[5] Džunuzović E, Marinović-Cinović M, Jeremić K, Nedeljković J. Influence of cubic $\alpha-\mathrm{Fe}_{2} \mathrm{O}_{3}$ particles on the thermal stability of poly(methyl methacrylate) synthesized by in situ bulk polymerization. Polymer Degradation and Stability 2009;97:701-4. doi:10.1016/i.polymdegradstab.2008.12.018.

[6] Majoni S, Su S, Hossenlopp JM. The effect of baron-containing layered hydroxyl salt (LHS) on the thermal stability and degradation kinetics of pol$\mathrm{y}$ (methyl methacrylate). Polymer Degradation and Stability 2010;95: 1593-604. doi:10.1016/j.polymdegradstab.2010.05.033.

[7] Laachachi A, Ferriol M, Cochez M, Cuesta J-ML, Ruch D. A comparison of the role boehmite $(\mathrm{AlOOH})$ and alumina $\left(\mathrm{Al}_{2} \mathrm{O}_{3}\right)$ in the thermal stability and flammability of poly(methyl methacrylate). Polymer Degradation Stability 2004;94:1373-8. doi:10.1016/j.polymdegradstab.2009.05.014.

[8] Orhan T, Isitman NA, Hacaloglu J, Kaynak C. Thermal degradation mechanisms of aluminium phosphate, melamine polyphosphate and zinc borate in poly(methyl methacrylate). Polymer Degradation Stability 2011;96:1780-7. doi: 10.1016/j.oplymdegradstab.2011.07.019.

[9] Laachachi A, Ruch D, Addiego F, Ferriol M, Cochez M, Cuesta J-ML. Effect of $\mathrm{ZnO}$ and organo-modified montmorillonite on thermal degradation of poly(methyl methacrylate) nanocomposites. Polymer Degradation and Stability 2009;94:670-8. doi:10.1016/j.polymdegradstab.2008.12.002.
[10] Sun X, Chen X, Liu X, Qu S. Optical properties of poly (methyl methacrylate)titania nanostructure thin films containing ellipsoid-shaped titania nanoparticles from ex-situ sol-gel method at low growth temperature. Applied Physics B 2011;103:391-8. doi:10.1007/s00340-010-4265-6.

[11] Khaled SM, Sui R, Charpentier PA, Rizkalla AS. Synthesis of $\mathrm{TiO}_{2}$-PMMA nanocomposite: using methacrylic acid as a coupling agent. Langmuir 2007; 23:3988-95. doi:10.1021/la062879n.

[12] Ahmad S, Ahmad S, Agnihotry SA. Synthesis and characterization of in situ prepared poly(methyl methacrylate) nanocomposites. Bulletin of Materials Science 2007;30:31-5. doi:10.1007/s12034-007-0006-9.

[13] Ling Z, Zhongshi L, Wenjun FA, Tianyou P. A novel polymethyl methacrylate (PMMA)-TiO2 nanocomposite and its thermal and photic stability. Wuhan University Journal of Natural Sciences 2006;11:415-8. doi:10.1007/ BF02832134.

[14] Hojjati B, Charpentier PA. Synthesis and kinetics of graft polymerization of methyl methacrylate from the RAFT coordinated surface of nano- $\mathrm{TiO}_{2}$. Journal of Polymer Science Part A: Polymer Chemistry 2008;46:3926-37. doi:10. 1002/pola.22724

[15] Hamming LM, Qiao R, Messersmith PB, Brinson LC. Effects of dispersion and interfacial modification on the macroscale properties of $\mathrm{TiO}_{2}$ polymer-matrix nanocomposites. Composites Science and Technology 2009;69:1880-6. doi: 10.1016/j.compscitech.2009.04.005.

[16] Patra N, Salerno M, Malerba M, Cozzoli PD, Athanassiou A. Improvement of thermal stability of poly (methyl methacrylate) by incorporation of colloidal $\mathrm{TiO}_{2}$ nanorods. Polymer Degradation Stability 2011;96:1377-81. doi:10.1016/ j.polymdegradstab.2011.03.020.

[17] Laachachi A, Ferriol M, Cochez M, Ruch D, Cuesta JML. The catalytic role of oxide in the thermooxidative degradation of poly (methyl methacrylate)- $\mathrm{TiO}_{2}$ nanocomposites. Polymer Degradation and Stability 2008;93:1131-7. doi:10. 1016/j.polymdegradstab.2008.03.006

[18] Chatterjee A. Effect of nano $\mathrm{TiO}_{2}$ addition on poly (methyl methacrylate): an exciting nanocomposite. Journal of Applied Polymer Science 2010;116: 3396-407. doi:10.1002/app.31883.

[19] Chatterjee A. Properties improvement of PMMA using nano $\mathrm{TiO}_{2}$. Journal of Applied Polymer Science 2010;118:2890-7. doi:10.1002/app.32567.

[20] Carp O, Huisman CL, Reller A. Photoinduced reactivity of titanium dioxide. Progress in Solid State Chemistry 2004;32:33-177. doi:10.1016/j.progsolidstchem.2004.08.001

[21] Young RA, editor. The Rietveld method. Oxford: Oxford University Press; 1993.

[22] Lutterotti L, Gialanella S. X-ray diffraction characterization of heavily deformed metallic specimens. Acta Metallurgica 1998;46:101-10. doi:10. 1016/S1359-6454(97)00222-X.

[23] Hartmann SR, Hahn EL. Nuclear double resonance in the rotating frame. Physical Review Online Archive 1962;128:2042-53. doi:10.1103/PhysRev. 128.2042.

[24] Lau C, Mi Y. A study of blending and complexation of poly (acrylic acid)/poly (vinyl pyrrolidone). Polymer 2002;43:823-9. doi:10.1016/S0032-3861(01) 00641-3.

[25] Conte P, Spaccini R, Piccolo A. State of art of CPMAS ${ }^{13}$ C-NMR spectroscopy applied to natural organic matter. Progress in Nuclear Magnetic Resonance Spectroscopy 2004;44:215-23. doi:10.1016/j.pnmrs.2004.02.002.

[26] Alamo RG, Blanco JA, Carrilero I. Measurement of the ${ }^{13} \mathrm{C}$ spin-lattice relaxation time of the non-crystalline regions of semicrystalline polymers by a CPMAS-based method. Polymer 2002;43:1857-65. doi:10.1016/S0032-3861(01) 00761-3.

[27] Vyazovkin S, Burnham AK, Criado JM, Maqueda LAP, Popescu C, Sbirrazzuoli N. ICTAC kinetics committee recommendations for performing kinetic computations on thermal analysis data. Thermochimica Acta 2011;520:1-19. doi:10. 1016/j.tca.2011.03.034.

[28] Saladino ML, Zanotto A, Chillura Martino D, Spinella A, Nasillo G, Caponetti E. Ce:YAG nanoparticles embedded in a PMMA matrix: preparation and characterization. Langmuir 2010;26:13442-9. doi:10.1021/la9042809.

[29] Eijkelenboom APAM, Maas WEJR, Veeman WS, Buning GHW, Vankan JMJ. Triple-resonance fluorine-19, proton, and carbon-13 CP-MAS NMR study of the influence of PMMA tacticity on the miscibility in PMMA/poly (vinylidene fluoride) (PVF2) blends. Macromolecules 1992;25:4511-8. doi:10.1021/ ma00044a009.

[30] Wang $\mathrm{H}$, Meng S, Xu P, Zhong W, Du Q Effect of traces of inorganic content on thermal stability of poly(methylmethacrylate) nanocomposites. Polymer Engineering and Science 2007;47:302-7. doi:10.1002/pen.20708.

[31] Lachaachi A, Cochez M, Ferriol M, Lopez-Cuesta JM, Leroy E. Influence of $\mathrm{TiO}_{2}$ and $\mathrm{Fe}_{2} \mathrm{O}_{3}$ fillers on the thermal properties of poly(methyl methacrylate) (PMMA). Materials Letters 2005;59:36-9.

[32] Holland BJ, Hay JN. The value and limitations of non-isothermal kinetics in the study of polymer degradation. Thermochimica Acta 2002;388:253-73. doi: 10.1016/S0040-6031(02)00034-5.

[33] Gao Z, Kaneko T, Hou D, Nakada M. Kinetics of thermal degradation of poly (methyl methacrylate) studied with the assistance of the fractionation conversion at the maximum reaction rate. Polymer Degradation and Stability 2004;84:399-403. doi:10.1016/j.polymdegradstab.2003.11.015.

[34] Vyazovkin S. A unified approach to kinetic processing of nonisothermal data. International Journal of Chemical Kinetics 1996;28:95-101. doi:10.1002/(sici) $\underline{1097-4601}$ 